\title{
Progress in research and development for REBCO coated conductors by reactive co-evaporation
}

\author{
S.S Oh ${ }^{*}$, a , H.S. Kim ${ }^{a}$, H.S. Ha ${ }^{a}$, R.K. Ko ${ }^{a}$, D.W. Ha ${ }^{a}$, H. Lee ${ }^{b}$, S.H. Moon ${ }^{\text {, }}$ and S.I. Yoo \\ ${ }^{a}$ Korea Electrotechnology Research Institute, Sungsan-gu, Changwon-si, Gyeongnam 641-120 Korea \\ b SuNAM Co.,Ltd., Wongok-myeon, Anseong-si, Gyeonggi-do 456-812, Korea \\ c Seoul National University, Gwanak-gu, Seoul 151-742, Korea
}

(Received 6 December 2013; revised or reviewed 19 December 2013; accepted 20 December 2013)

\begin{abstract}
This paper reviews recent progress in research and development $(R \& D)$ of reactive co-evaporation for high performance REBCO coated conductors in Korea. Two types of reactive co-evaporation methods were developed for the deposition of SmBCO and GdBCO superconducting layers respectively on the IBAD (Ion Beam Assisted Deposition)-MgO template in the Korean coated conductor project. Batch type reactive co-evaporation equipment and its processing were developed for SmBCO coated conductors at Korea Electrotechnology Research Institute (KERI) in conjunction with the Korea Advanced Institute of Science and Technology (KAIST), and a very high critical current exceeding $1,000 \mathrm{~A} / \mathrm{cm}$ at $77 \mathrm{~K}$ in the self field was achieved through the optimization of deposition parameters. Reel-to-reel type reactive co-evaporation processing with a high conversion rate was also developed, while long length GdBCO coated conductors have been routinely produced by SuNAM Co. The minimum critical current of $422 \mathrm{~A} / \mathrm{cm}-\mathrm{w}$ at $77 \mathrm{~K}$ in self field was confirmed for $1 \mathrm{~km}-$ long GdBCO tape.
\end{abstract}

Keywords : SmBCO, GdBCO, coated conductor, evaporation, critical current

\section{INTRODUCTION}

R\&D of deposition technologies for RE (RE; Y, Sm, Gd, $\mathrm{Nd}, \mathrm{Ho}) \mathrm{Ba}_{2} \mathrm{Cu}_{3} \mathrm{O}_{7-\mathrm{y}}(\mathrm{REBCO})$ coated conductor $(\mathrm{CC})$ have been carried out extensively around the world since the early 1990s. Crystal grains of REBCO superconductor could be bi-axially aligned due to the developments of RABiTS [1-3] and IBAD template technologies [4-6], and critical current density $\left(J_{c}\right)$ was greatly improved as a result.

A lot of efforts have been focused on the fabrication of long length CCs by superconductor manufacturers, and the production of $1 \mathrm{~km}$ - long tape is now technically available $[7,8]$.

Many research prototypes for power cables [9-11], motors [12], fault current limiters [13], SMES (Superconducting Magnetic Energy Storage) [14] and transformers [15] using CC were demonstrated, and the projects for the application of superconducting AC power cables in a real power grid are now in progress in several countries [16, 17].

Though several hundred meters-long CC tapes are sold commercially, technical issues such as non-uniformity of $I_{c}$, high fabrication cost, higher AC loss and so on need to be resolved to allow the spread of $\mathrm{CC}$ in a variety of application fields.

A full-scale R\&D for CC was performed over a 10 year period in the DAPAS (Development of Advanced Power

\footnotetext{
* Corresponding author: ssoh@keri.re.kr
}

systems by Applied Superconductivity technology) project, which began in 2001 in Korea. KERI is a research management institution and many university research groups joined this project to develop basic and fundamental technologies. In the third research phase of this project (2007 - 2011), SuNAM Co. joined as an industrial partner in charge of production technology. KERI and SuNAM Co. concentrated on the enhancement of critical current $\left(I_{c}\right)$ and the production of long length $\mathrm{CC}$ tape respectively in the project.

At the beginning of the DAPAS CC project, research of both Ni alloy textured substrate and IBAD-MgO textured template was performed, and various deposition technologies such as PLD (Pulsed Laser Deposition), MOD (Metal Organic Deposition) and MOCVD (Metal Organic Chemical Vapor Deposition) were also tried for the fabrication of a superconducting REBCO layer. In the third research phase of the project, IBAD-MgO and RCE (Reactive Co-Evaporation) were finally selected as main processes considering the performance and the fabrication cost of CC.

Continuous fabrication technology of a bi-axially textured IBAD-MgO layer and its deposition equipment were successfully developed in the project, and they accelerated CC research in Korea. KAIST group developed an original batch type RCE system called EDDC (Evaporation using Drum in Dual Chamber) and demonstrated $7.5 \mathrm{~m}$-long SmBCO CC using a Ni textured substrate [18].

KERI modified the EDDC system and tried to fabricate a 
longer SmBCO tape using a IBAD-MgO template which was developed by Seoul National University (SNU) and SuNAM Co. for the technical verification of high $I_{c}$ tape in long length.

SuNAM Co. developed a reel-to-reel process of RCE for the continuous fabrication of long length tape and established a high speed conversion process [19].

In this article, representative research results and the progress of $R \& D$ achieved in the third research phase of the DAPAS CC project, which officially ended in March of 2011, are introduced. The outline of RCE processes for the deposition of $\mathrm{SmBCO}$ and $\mathrm{GdBCO}$ layer are also described.

\section{COATED CONDUCTOR STRUCTURE AND IBAD-MgO TEMPLATE}

The structure of DAPAS CC is schematically illustrated in Figure 1. Amorphous layers of $\mathrm{Al}_{2} \mathrm{O}_{3}$ and $\mathrm{Y}_{2} \mathrm{O}_{3}$ were deposited on the surface of Hastelloy tape which was continuously electro-polished, and first textured buffer layer, $\mathrm{MgO}$ was deposited successively using IBAD technology and finally a $\mathrm{LaMnO}_{3}$ (LMO) layer was deposited for the buffered substrate. We selected $\mathrm{MgO}$ as a first textured material because its excellent bi-axial texturing was verified [6] in a very thin film, and focused on the continuous fabrication of long length IBAD-MgO tape using the reel-to-reel process.

In the second research phase (2004 - 2007), a reel-to-reel R\&D deposition system with e-beam evaporator and a Kaufman type auxiliary ion gun was manufactured for the fabrication of long length IBAD-MgO tape. Using this system, homo-epi $\mathrm{MgO} / \mathrm{IBAD}-\mathrm{MgO} / \mathrm{Y}_{2} \mathrm{O}_{3} / \mathrm{Al}_{2} \mathrm{O}_{3}$ layers could be deposited on electro-polished Hastelloy tape, followed by LMO deposition by PLD.

The in-plane texture of IBAD-MgO layer was analyzed with X-ray phi-scan for $\mathrm{MgO}$ (220) crystal plane, and the average FWHM was confirmed to be $5.86^{\circ}$ for $13 \mathrm{~m}$-long tape [20].

As shown in Table 1, the production speed of homo-epi $\mathrm{MgO}$ and LMO was $\sim 70$ and $50 \mathrm{~m} / \mathrm{h}$ respectively in the R\&D deposition system, and they were speed-limiting steps in the production of buffered substrate tape. However, IBAD-MgO, homo-epi $\mathrm{MgO}$ and LMO could be deposited with a higher speed of $360 \mathrm{~m} / \mathrm{h}$ using a single in-line deposition system which was installed in the pilot production line at SuNAM Co. Total production speed of the buffered substrate was greatly enhanced in this pilot deposition system. Long length buffered substrate tapes are now routinely produced by SuNAM Co. In the pilot deposition system, the epitaxy of the $\mathrm{MgO}$ layer during the deposition can be monitored using an in-situ RHEED screen. Typical patterns obtained from RHEED for IBAD-MgO and Homo-epi MgO layer are shown in Figure 2. FWHM of MgO (220) and LMO(110) was evaluated to be $3.82^{\circ}$ and $4.73^{\circ}$ respectively for the substrate tape, which was fabricated under optimized conditions using the pilot

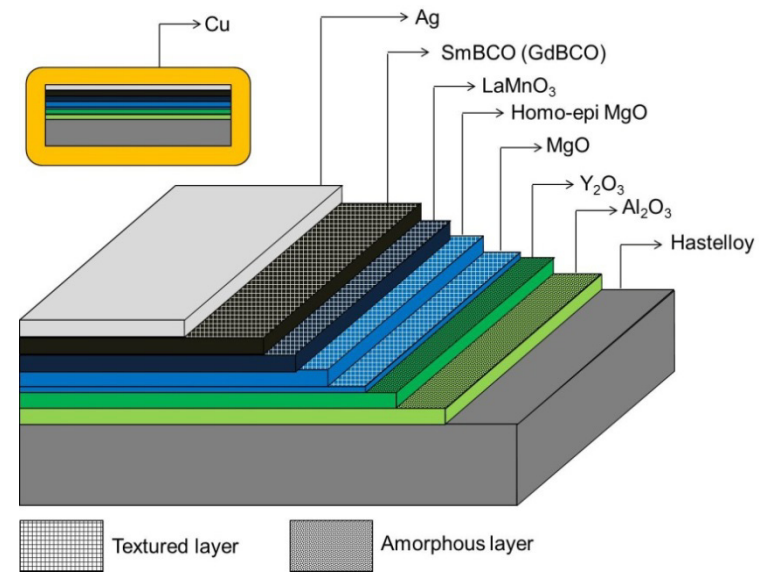

Fig. 1. Schematic architecture layout of DAPAS coated conductor.

deposition system as shown in Figure 2. Therefore, the in-plane texture of $\mathrm{MgO}$ and $\mathrm{LMO}$ turned out to be improved in the pilot system.

\section{HIGH PERFORMANCE SmBCO TAPE}

Though we tried several processes for the deposition of a superconducting REBCO layer at the beginning of the DAPAS CC project, EDDC was finally selected for the deposition of the SmBCO layer, and the second model of EDDC equipment was manufactured for the capability of $100 \mathrm{~m}$ fabrication length and installed at KERI in 2005.

Figure 3 shows the schematic layout of the KERI EDDC system, and the variation of oxygen partial pressure and temperature during the deposition in the system. Precursor elements of $\mathrm{Sm}, \mathrm{Ba}, \mathrm{Cu}$ are evaporated in a lower vacuum chamber using induction and resistive heating. Quartz Crystal Microbalance (QCM) sensors with guide tubes were used to detect the deposition rate of each element, and a differential pumping system was attached to reduce the oxygen flow from the upper reaction chamber to the lower evaporation chamber. Halogen heaters for heating the substrate were mounted both inside and outside the drum, and the upper chamber was filled with oxygen gas using the nozzle. Buffered substrate with the structure of LMO / homo-epi $\mathrm{MgO} / \mathrm{IBAD}-\mathrm{MgO} / \mathrm{Y}_{2} \mathrm{O}_{3} /$ $\mathrm{Al}_{2} \mathrm{O}_{3} /$ Hastelloy was wound on the inconel drum in the upper chamber.

TABLE I

PROCESS SPEED OF EACH LAYER IN R\&D AND PILOT SYSTIMS.

\begin{tabular}{ccc}
\hline Process Step & R\&D system ('08) & Pilot system ('09) \\
\hline $\mathrm{Al}_{2} \mathrm{O}_{3}$ & $210 \mathrm{~m} / \mathrm{hr}$ & $600 \mathrm{~m} / \mathrm{hr}$ \\
$\mathrm{Y}_{2} \mathrm{O}_{3}$ & $500 \mathrm{~m} / \mathrm{hr}$ & $(1$ system) \\
\hline IBAD-MgO & $600 \mathrm{~m} / \mathrm{hr}$ & $360 \mathrm{~m} / \mathrm{hr}$ \\
$\mathrm{Homo-epi} \mathrm{MgO}$ & $\sim 70 \mathrm{~m} / \mathrm{hr}$ & $(1$ system) \\
LMO & $\sim 50 \mathrm{~m} / \mathrm{hr}$ & \\
\hline
\end{tabular}


Evaporated $\mathrm{Sm}, \mathrm{Ba}$ and $\mathrm{Cu}$ atoms in $\sim 10^{-5}$ Torr vacuum state fly toward the substrate on the drum, which was heated to 700 to $850^{\circ} \mathrm{C}$ in the upper chamber forming a mixture on the LMO surface.

It converts to a superconducting $\mathrm{SmBCO}$ compound through the diffusion and the reaction process in the upper chamber, where oxygen partial pressure was maintained at 15 mTorr. A nano-scale thin SmBCO layer is formed through the deposition-diffusion-reaction process during one cycle rotation of the drum and SmBCO crystal grows to a thick film during repeated rotation.

In second research phase, the highly-textured $\mathrm{SmBCO}$ layer was confirmed to be increased to a thickness of 2.2 $\mu \mathrm{m}$. A minimum $I_{c}$ of $305 \mathrm{~A} / \mathrm{cm}-\mathrm{w}$ was achieved at the $27 \mathrm{~m}$ section of the $93 \mathrm{~m}$ long $\mathrm{SmBCO}$ tape at $77 \mathrm{~K}$ in self-field. The $I_{c}$ over $250 \mathrm{~A} / \mathrm{cm}-\mathrm{w}$ at $77 \mathrm{~K}$ was confirmed in the whole length, but this included several delaminated parts with almost zero $I_{c}$ values [21].

Figure 4 shows annual $I_{c}$ records for EDDC-SmBCO fabricated on an IBAD-MgO template from 2006 to March of 2011. $I_{c}$ increased steadily every year except 2009. The main deposition parameters, such as composition, substrate temperature and oxygen partial pressure, were systematically optimized through the modification of the EDDC system for the challenge of achieving a high $I_{c}$ over $1,000 \mathrm{~A} / \mathrm{cm}-\mathrm{w}$ at $77 \mathrm{~K}$. In order to get such a high $I_{c}$ value, a high $J_{c}$ should be maintained in the thicker film. In the optimized composition, $5 \mu$ m-thick SmBCO film was deposited on a $4 \mathrm{~mm}$ - wide IBAD-MgO template tape for 2 hours and 20 minutes. According to the optimization of EDDC parameters, an $I_{c}$ over $1,000 \mathrm{~A} / \mathrm{cm}$ at $77 \mathrm{~K}$ in self field was successfully achieved in March of 2011.

After $2 \mathrm{~mm}$-wide bridge patterning by a laser striation system, transport critical current of $12 \mathrm{~cm}$ sections for 5 $\mu \mathrm{m}$-thick SmBCO tape was measured with a definition of 1 $\mu \mathrm{V} / \mathrm{cm}$ at $77 \mathrm{~K}$ in the self-field. In 8 sections out of a total of 13 sections of $2 \mathrm{~m}$-long tape, $I_{c}$ values of 1170 to 1280

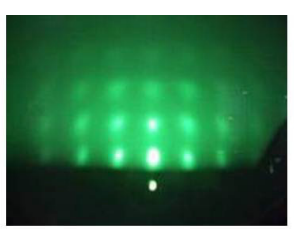

IBAD-MgO
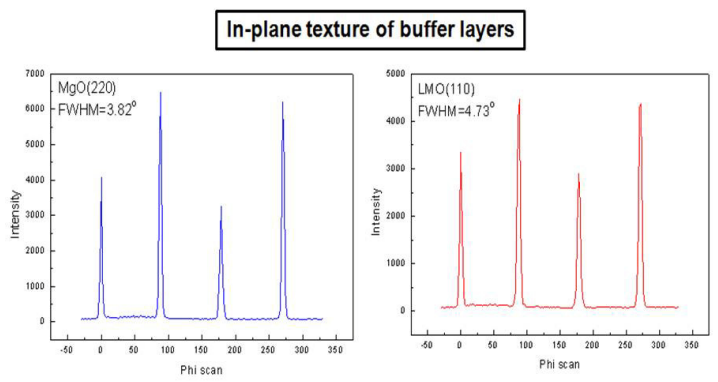

Fig. 2. RHEED patterns and X-ray phi-scan showing in-plane textures of $\mathrm{MgO}$ and LMO layers for buffered substrate fabricated in the pilot system of SuNAM Co.

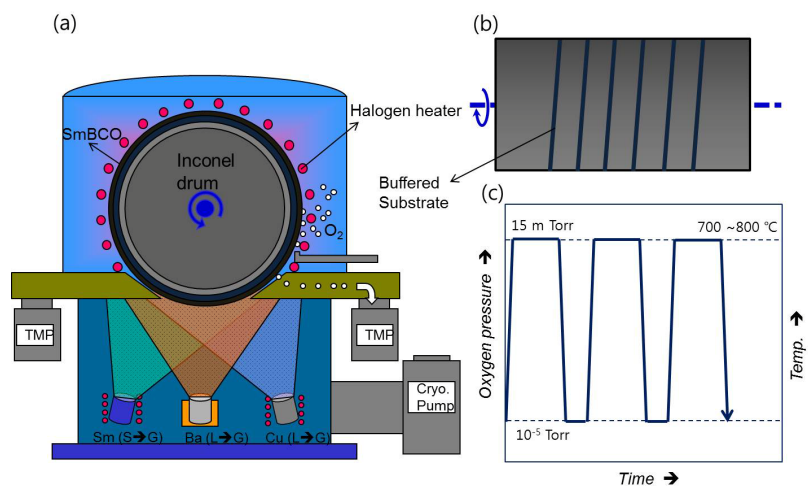

Fig. 3. Schematic layout of EDDC system (a) and the variation of oxygen pressure and temperature with time (b).

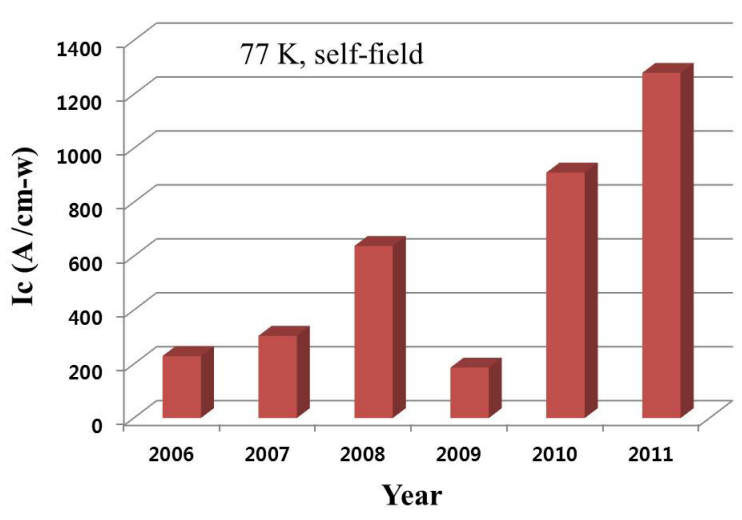

Fig. 4. Annual $I_{c}$ record of EDDC-SmBCO tape.

A/cm-w were confirmed. $J_{c}$ over $2.5 \mathrm{MA} / \mathrm{cm}^{2}$ was realized in $5 \mu \mathrm{m}$-thick SmBCO film. The details of the optimization process and the correlation between the high $I_{c}$ and microstructure regarding $5 \mu \mathrm{m}$-thick SmBCO CC will be reported in the near future in another paper.

Field dependency of normalized $J_{c}$ for EDDC-SmBCO $\mathrm{CC}$ when the magnetic field is applied normally to the tape surface was investigated. As shown in Figure 5, compared to commercial YBCO CC without pinning centers, a higher field dependency of $J_{c}$ was confirmed across the whole temperature range for $\mathrm{SmBCO} \mathrm{CC}$. To date, no artificial doping technology to enhance the flux pinning force has been introduced in our EDDC process. Thus, it was considered that a pure SmBCO film deposited by EDDC possesses a superior in-field property.

Figure 6 shows the microstructures of $5 \mu \mathrm{m}$-thick SmBCO analyzed by SEM and TEM. SmBCO crystals were grown epitaxially up to $5 \mu \mathrm{m}$-thickness, and several rectangular particles resulting from a-axis growth were found on the surface of SmBCO. However, it was thought that the number and distribution of particles was not sufficiently dominant to hinder the super-current. It was observed that the interface of each layer is smooth, and epitaxial growth was transferred across the interface. 


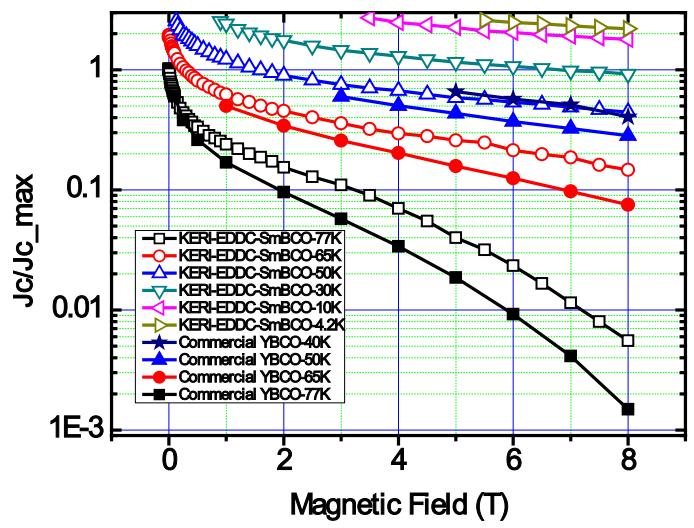

Fig. 5. Field dependence of critical current for EDDC-SmBCO tape.
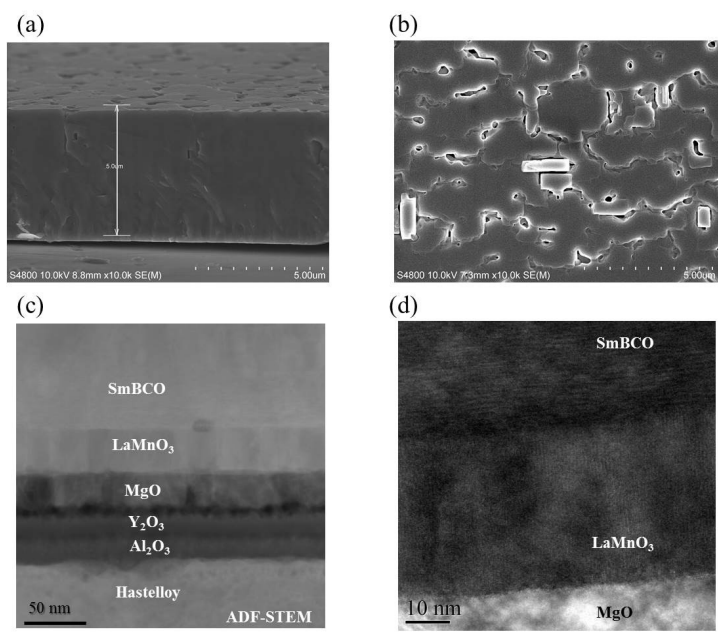

Fig. 6. SEM images of cross-section (a) and free-surface (b), and TEM images of cross-section (a) and (b) for SmBCO film.

\section{LONG LENGTH GdBCO TAPE}

A continuous reel-to-reel RCE-DR (Deposition and Reaction) process was developed for the fabrication of long length CC tape by SuNAM Co. GdBCO was selected as a material for the deposition of the superconducting layer. RCE-DR has a common ground with EDDC in the sense that precursor metal elements are co-evaporated and followed by reaction, but the conversion path was different from that of batch type EDDC.

Figure 7 shows the schematic layout of the RCE-DR process that was employed by SuNAM Co. An amorphous metal film was deposited on the substrate by e-beam and followed by the conversion in the specially fabricated quartz tube furnace divided into two parts featuring high and low oxygen pressures.

Amorphous film deposited with a rate of $6 \sim 10 \mathrm{~nm} / \mathrm{s}$ at low temperature in $10^{-5}$ Torr vacuum atmosphere is transformed to $\mathrm{Gd}_{2} \mathrm{O}_{3}$ and a liquid phase while it passes through the low oxygen pressure furnace region. GdBCO solid phase was formed by the peritectic reaction while it

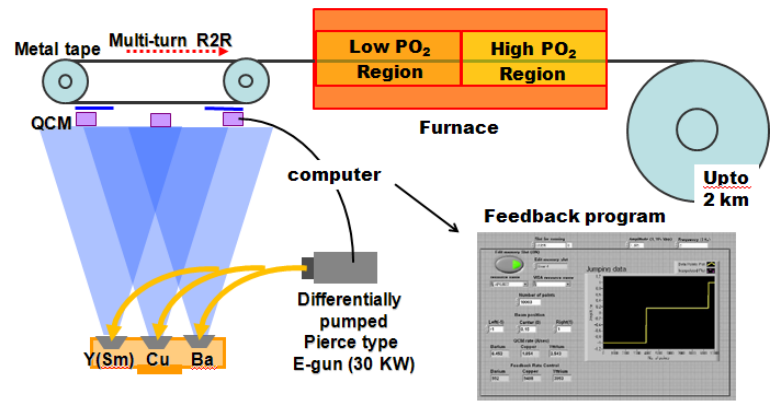

Fig. 7. Schematic layout of the RCE-DR process at SuNAM Co. (a)

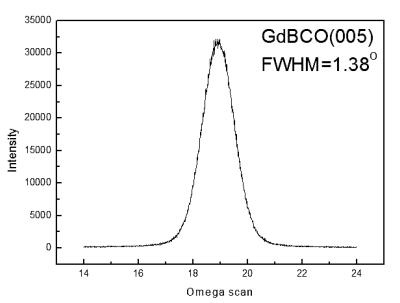

(b)

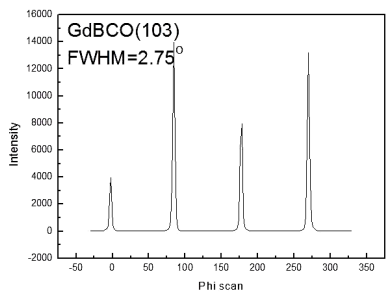

Fig. 8. X-ray Phi and Omega-scans for GdBCO (005) and (103) planes.

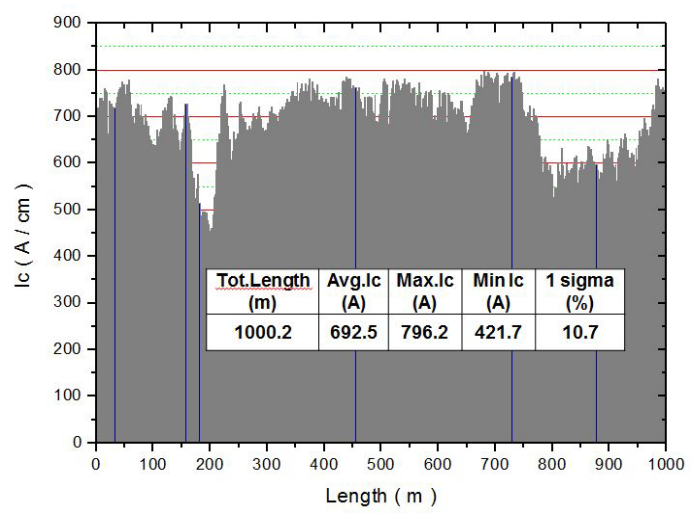

Fig. 9. Distribution of critical current for km-long GdBCO CC.

passes through the high oxygen pressure region. The main feature of the RCE-DR process is the fast conversion from the amorphous state to the superconducting phase, which occurs within one minute.

Figure 8 shows the degree of crystal texturing in GdBCO tape fabricated by SuNAM Co. A FWHM value of XRD omega and phi-scan from GdBCO (005) and (103) planes were estimated to be low as $1.38^{\circ}$ and $2.75^{\circ}$ respectively.

The minimum $I_{c}$ was found to be $422 \mathrm{~A} / \mathrm{cm}-\mathrm{w}$, though its distribution is non-homogenous. The value of $I_{c} \times \mathrm{L}$ is 421,700 Am [8].

\section{CONCLUSION}

Fundamental technologies for a high critical current and 
long length of coated conductor have been developed in Korea. A continuous reel-to-reel fabrication process of highly-textured IBAD-MgO template tape was developed, and a production line was installed in the company. IBAD-MgO template technology accelerated coated conductor R\&D in Korea. Two types of reactive co-evaporation processes were developed. A high critical current exceeding $1,000 \mathrm{~A} / \mathrm{cm}$ was achieved for $\mathrm{SmBCO}$ tape by the EDDC method. The RCE-DR process with a high rate conversion for the deposition GdBCO layer was successfully developed in the DAPAS coated conductor project. Fabrication technology for long length GdBCO CC was established and the high critical current $1 \mathrm{~km}$-long GdBCO tape was demonstrated.

\section{ACKNOWLEDGMENT}

This research was supported by a grant from Center for Applied Superconductivity Technology of the 21 st Century Frontier R\&D Program funded by the Ministry of Science.

\section{REFERENCES}

[1] A. Goyal, D. P. Norton, J. D. Budai, M. Paranthaman, E. D. Specht, D. M. Kroeger, D. K. Christen, Q. He, B. Saffian, F. A. List, D. F. Lee, P. M. Martin, C. E. Klabunde, E. Hartfield, and V. K. Sikka, "High critical current density superconducting tapes by epitaxial deposition of YBa2Cu3Ox thick films on biaxially textured metals", Appl. Phys. Lett., vol. 69, pp.1795 - 1797, 1996.

[2] V. Subramanya Sarma, J. Eickemeyer, A. Singh, L. Schultz, B. Holzapfel, "Development of high strength and strongly cube textured $\mathrm{Ni}-4.5 \% \mathrm{~W} / \mathrm{Ni}-15 \% \mathrm{Cr}$ composite substrate for coated conductor application", Acta Materialia, vol.51, pp.4919 - 4927 2003

[3] D. Verebelyi, U. Schoop, C. Thieme, X. Li, W. Zhang, T. Kodenkandath, A. P. Malozemoff, N. Nguyen, E. Siegal, D. Buczek, J. Lynch, J. Scudiere, M. Rupich, A. Goyal, E. D. Specht, P. Martin and M. Paranthaman, "Uniform performance of continuously processed MOD-YBCO-coated conductors using a textured Ni-W substrate", Supercond. Sci. Technol., vol. 16, L19 - L22, 2003.

[4] I. Iijima, N. Tanabe, O. Kohno, and Y. Ikeno, "In-plane aligned $\mathrm{YBa} 2 \mathrm{Cu} 3 \mathrm{O} 7-\mathrm{x}$ thin films deposited on polycrystalline metallic substrates", Appl. Phys. Lett., vol.60, pp.769-771, 1992.

[5] C.P. Wang, K. B. Do, M. R. Beasley, T. H. Geballe, and R. H. Hammond, "Deposition of in-plane textured $\mathrm{MgO}$ on amorphous Si3N4 substrates by ion-beam-assisted deposition and comparisons with ion-beam-assisted deposited yttria-stabilized-zirconia", Appl. Phys. Lett., vol.71, pp.2955 - 2957, 1997.

[6] P.N. Arendt and S.R. Foltyn, Biaxially Textured IBAD-MgO Templates for YBCO-Coated Conductors, MRS Bulletin, vol.29, pp.543 - 550, 2004

[7] D.W. Hazelton, Progress in Coated Conductor at SuperPower, Low Temperature High Field Superconductor Workshop (LTHFSW2010), November 8-10, 2010, Monterey, CA, USA.
[8] S.H. Moon, R\&D of Coated Conductors in Korea, The 20th International Superconductivity Industrial Summit, Oct. 31 - Nov. 1, 2011, Gonjiam, Korea.

[9] S. Honjo, T. Mimura, Y. Takahashi, "Present status of the development of superconducting power cable", Physcia $C$, vol.1-4, pp.11-14, 2000.

[10] M.J. Gougea, M.J. Colea, J.A. Demkoa, P.W. Fishera, C.A. Fostera, R. Grabovickica, D.T. Lindsayb, J.W. Luea, M.L. Rodenb, J.C. Tolbertb, "High-temperature superconducting tri-axial power cable", Physcia C, vol.392-396, pp.1180-1185, 2003

[11] S. Mukoyama, M. Yagi, H. Hirata, M. Suzuki, S. Nagaya, N. Kashima, and Y. Shiohara, "Development of YBCO High-Tc Superconducting Power Cables", Furukawa Review, vol.35, pp.18 $-22,2009$.

[12] D. U. Gubser, "Superconducting motors and generators for naval applications", Physcia C, vol.392-396, pp.1192 - 1195, 2003.

[13] T. Yazawa, K. Koyanagi, M. Takahashi, K. Toba, H. Takigami, M. Urata, Y. Iijima, T. Saitoh, N. Amemiya, Y. Shiohara, T. Ito, "Development of $6.6 \mathrm{kV} / 600$ A superconducting fault current limiter using coated conductors", Physcia C, vol.469, pp.1740 1744, 2009.

[14] N. Atomura, T. Takahashi, Y. Chiba, M. Tsuda, T. Hamajima, K. Shikimachi, N. Hirano, S. Nagaya, "Homogeneous current distribution experiment in a multi-laminated HTS tape conductor for a double-pancake coil of SMES", Physcia C, vol.471, pp.1396 1398, 2011.

[15] K. Funaki, M. Iwakuma, K. Kajikawa, M. Hara, J. Suehiro, T. Ito, Y Takata, T. Bohno, S. Nose, M. Konno, Y. Yagi, H. Maruyama, T.Ogata, S.Yoshida, K. Ohashi, H.Kimura, K.Tsutsumi, "Development of a $22 \mathrm{kV} / 6.9 \mathrm{kV}$ Single-phase Model for a 3MVA HTS Power Transformer", IEEE Trans. Appl. Supercond., vol.1, pp.1578 - 1581, 2001

[16] J. F. Maguire, F. Schmidt, S. Bratt, T. E. Welsh, J. Yuan, A. Allais, and F. Hamber, "Development and Demonstration of a HTS Power Cable to Operate in the Long Island Power Authority Transmission Grid”, IEEE Trans. Appl. Supercond., vol. 17, pp.2034 - 2037, 2007.

[17] S. Honjo, T. Mimura, Y. Kitoh, Y. Noguchi, T. Masuda, H.Yumura, M.Watanabe, M. Ikeuchi, H. Yaguchi, and T. Hara, "Status of Superconducting Cable Demonstration Project in Japan", IEEE Trans. Appl. Supercond., vol.21, 967 - 971, 2011.

[18] B. S. Lee, K. C. Chung, S. M. Lim, H. J. Kim, D. Youm and C. Park, "Fabrication of $\mathrm{Sm} 1 \mathrm{Ba} 2 \mathrm{Cu} 3 \mathrm{O} 7$ coated conductors using the co-evaporation method", Supercond. Sci. and Technol., vol. 17, pp. $580-584,2004$

[19] S.M. Choi, J.W. Lee, G.H..Shin, J.H. Lee, G.W.Hong, S.H. Moon, and S.I.Yoo, "Characteristics of high-Jc GdBCO coated conductors fabricated by the RCE-DR process", IEEE Trans. Appl. Supercond., 2013 (in press).

[20] K.P. Ko, H.S. Ha, H.K. Kim, K.K. Yu, R.K. Ko, S.H. Moon, S.S. Oh C. Park, S.I. Yoo, "Fabrication of highly textured IBAD-MgO template by continuous reel-to-reel process and its characterization", Physica C, vol.463-465, pp.564-567, 2007.

[21] S. S. Oh, H.S. Ha, H. S.Kim, R.K. Ko, K.J. Song, D. W. Ha, T. H. Kim, N. J. Lee, D. Youm, J. S. Yang, H. K. Kim, K. K. Yu, S. H. Moon, K. P. Ko and S. I. Yoo, "Development of long-length SmBCO coated conductors using a batch-type reactive co-evaporation method", Supercond. Sci. and Technol. vol.21, pp.034003-034008, 2008. 